\title{
CAPITALISMO E ONTOLOGIA DA BIOÉTICA: O PROCESSO DE TRABALHO DE MÉDICOS DE FAMÍLIA NA ITÁLIA
}

\author{
CAPITALISM AND THE ONTOLOGY OF BIOETHICS:THE FAMILY PHYSICIAN WORK PROCESS IN ITALY
}

CAPITALISMO Y ONTOLOGÍA DE LA BIOÉTICA: EL PROCESO DE TRABAJO DE LOS MÉDICOS

DE FAMILIA EN ITALIA

Rita de Cássia Gabrielli Souza Lima ${ }^{1}$

Marta Inez Machado Verdi ${ }^{2}$

Resumo $\mathrm{O}$ artigo examina as fragilidades que permeiam as inter-relações estabelecidas no processo de trabalho de médicos de família italianos para conhecer possíveis conflitos éticos. Trata-se de um estudo de campo, de abordagem qualitativa e caráter exploratório-descritivo, realizado em 2007, na província de Roma, região do Lácio, Itália, com médicos de família italianos conveniados ao Serviço Sanitário Nacional. Analisados à luz da bioética cotidiana, os resultados mostram conflitos éticos gerados diretamente pelo modelo de organização de atenção em saúde do Serviço Sanitário Nacional e pelo mercado da indústria farmacêutica e indiretamente pela sociedade, tendo como pano de fundo o capitalismo em sua face neoliberal.

Palavras-chave médicos de família; bioética; capitalismo.
Abstract This paper examines the weaknesses that permeate the interrelationships established in the work process Italian family physicians use to get to know potential ethical conflicts. This field study used a qualitative approach, was exploratory-descriptive in nature, and was conducted in 2007 in the province of Rome, region of Lazio, Italy, among Italian family physicians hired under the National Health Service. Analyzed in the light of everyday bioethics, the results show ethical conflicts generated directly by the health care organization model used by the National Health Service, by the pharmaceutical industry's market, and indirectly by the society, with the backdrop of neoliberal capitalism.

Keywords family physicians; bioethics; capitalism. 


\section{Introdução}

Embora cada tempo histórico revele um modelo de organização social, uma característica é comum aos distintos processos de viver: o homem busca permanentemente a sua superação. Neste percurso, depara-se com múltiplos fenômenos naturais, sociais e políticos que demandam escolhas as quais, por sua vez, pressupõem tensão, conflito, disposição e dependência. Tensão e conflito já que, para escolher, o homem transita entre o desejo e a necessidade, entre a renúncia e a concessão. Disposição, pois, ao optar por um caminho em detrimento de outro, deve estar livre e consciente para enfrentar prováveis percalços e mudanças. Dependência, pelo fato de o homem ser um sujeito político-social com responsabilidades e vulnerável a mutações e influências advindas do modelo de organização social.

Na visão lacaniana, o desejo "tem uma ausência de fundo" (Abbagnano, 2007, p. 283): é falta, transcendência, desejo de outro desejo e, para permanecer vivo, pede para ser vivido na linguagem, diferentemente da necessidade que se realiza no campo do real, condicionada a um estado de dependência. A busca daquilo que falta movimenta o desejo humano, e o encontro com a necessidade satisfeita subsidia a concretização da existência humana. Desse modo, o homem deseja o que lhe falta e necessita de elementos concretos para viver, dentre eles o trabalho, que é "o homem mesmo, o seu modo específico de ser e de fazer-se homem (...) a própria realização ou produção de sua vida" (Abbagnano, 2007, p. 1.149).

Nessa perspectiva, a falta, expressa como necessidade, parece carregar a representação da tendência humana em aproximar o desejo da necessidade, no afã de fazer da vida um contínuo movimento de superação em busca de satisfação. Os conflitos éticos poderiam ser pensados como um produto que emerge desse ideal de aproximação, ou seja, da concorrência de valores que circulam nessa dinâmica relacional imaginária.

O presente artigo é fruto do desdobramento de pesquisa de mestrado realizada no Brasil e na Itália, em 2007, que buscou implicações éticas presentes nos discursos de médicos de família sobre a autonomia do sujeito em seu processo de cuidado e solidariedade na atenção primária à saúde (APS). Reforçando o entendimento de que a pesquisa qualitativa se desenvolve com liberdade em setting natural, no qual o pesquisador tenta buscar as significações de pessoas ou grupos sociais para 'as coisas que acontecem' em suas vidas (Turato, 2003), agregou-se ao instrumento desta pesquisa uma questão aberta para dar continência ao desejo/necessidade demonstrado por médicos de família: o de expressar as fragilidades que permeavam o seu cotidiano do processo de trabalho e analisá-las à luz da bioética.

A historicidade da medicina de família italiana é reconhecida mundialmente, pois durante três séculos - do século XVII ao início do século XX - 
as ações dessa área médica foram sustentadas pelo caráter antropológico-social e pelo reconhecimento da sociedade italiana. A partir do século XX, cedendo aos encantos da nova ordem que determinou a construção do médico ideal (aquele tecnicamente preparado e civilmente empenhado), a cultura da medicina de família italiana, até então fortemente humanitária e laica, e que compreendia o somático como humano e o humano como social, começou a circular publicamente à luz de novos arranjos embasados em avanços científicos e tecnológicos (Cosmacini, 2005).

As ações da medicina de família italiana são produtos dos serviços de APS. Diferentemente do Brasil, a Itália não tem um 'sistema único de saúde' com uma política nacional para a APS fundamentada em abordagem interdisciplinar. A Reforma Sanitária italiana, conquistada em 1978 como resposta ao amadurecimento orgânico de uma luta travada pelos partidos italianos de esquerda, desde a década de 1960, optou não por uma entidade sistêmica, mas por um serviço sanitário: o Serviço Sanitário Nacional (SSN). Esta escolha se deu para afastar a possibilidade de a saúde da sociedade italiana ser considerada "um ente (...) separado do corpo do Estado (...) somente médico-terapêutico (...) sem tendência unificadora" (Berlinguer, 2011, p. 2.130; Berlinguer, 1979, p. 9).

A epistemologia do SSN tem como base teórica o princípio socialista de "saúde como bem comum, distribuído desigualmente entre as classes e as regiões", As ações dos serviços de APS são organizadas em âmbito territorial urbano e rural, de modo que "atravesse a existência de todos": da sociedade (com necessidades de cuidado) e da classe trabalhadora (no escopo deste texto, a medicina de família) (Berlinguer, 1979, p. 9).

Com base nesta epistemologia, elegeu-se a bioética como referencial de análise da relação desejo/necessidade, expressa por médicos de família italianos. Esta escolha está vinculada aos seguintes preceitos: 1) a compreensão de bioética como uma produção social e um discurso anterior à política; 2) o argumento de a interface entre a bioética e APS italiana ser uma possibilidade para refletir as limitações da prática, dado que o significado da conduta humana é intrínseco ao produto humano, e este é gestado por escolhas que estão assentadas em um modelo de organização social; 3) a relevância da APS italiana, após a conquista do conceito de saúde como bem ético por um movimento sanitário ético e político - a Reforma Sanitária italiana; 4) a visão de saúde como produção sociocultural, em cujos condicionantes está a satisfação profissional; 5) o entendimento de que pessoas competentes cognitivamente são responsáveis pelas ações realizadas e pelos efeitos sociais gerados; e 6) por fim, a percepção de que os conflitos éticos são tensões relacionais consequentes do modo como o homem passou a organizar a dimensão desejo/necessidade em suas ações a partir da modernidade, tensões estas que demandam análise crítica. 
A análise será conduzida pela Bioética Cotidiana, referencial de ética aplicada, proposto por Giovanni Berlinguer, e compromissado com as questões humanas e tensões correlatas produzidas nas relações cotidianas, em seus contextos político, cultural e social. A Bioética Cotidiana é um campo de saber complexo que requer a aproximação com abordagens pluralísticas, laicas e multidisciplinares, pois entende o fenômeno humano como uma produção social cotidiana de caráter heterogêneo que, para avançar e colocarse a serviço de um mundo coletivamente construído por pessoas satisfeitas, demanda um processo ético compartilhado (Lima, Verdi, 2013).

\section{O percurso metodológico}

Trata-se de um estudo empírico, de abordagem qualitativa e caráter exploratório-descritivo realizado em 2007. Os sujeitos de pesquisa foram médicos de família, conveniados ao SSN, atuantes na grande Roma, região do Lácio, Itália, graduados em medicina entre 1975 e 2000. Todos possuíam especializações em outras áreas médicas, mas exerciam somente a medicina de família na modalidade medicina de grupo.

A pesquisa foi realizada em dois contextos da grande Roma. Em uma cidade jovem, extensa territorialmente, com população aproximada de 100 mil habitantes, projetada por arquitetos e fundada estrategicamente no século XX para dar suporte ao desenvolvimento industrial, na qual as atividades profissionais revelam o ritmo frenético que desenha o cotidiano dos italianos romanos. E em outra cidade, de origem latina, etrusca e volsca, com 50 mil habitantes, cuja historicidade inicia-se no século VI. Na Idade Média, essa cidade foi uma das poucas autônomas da região do Lácio a conservar vida própria. Proclamou a República no século XVIII, viu-se destruída pela Segunda Guerra Mundial, reconstruiu-se com coragem e hoje se apresenta como uma bela cidade, tranquila e acolhedora, cujo espaço urbano é um museu aberto, e o rural, basicamente agrícola (Lima, 2008).

O processo de solicitação e autorização em nível institucional, bem como a seleção dos participantes, deu-se por meio de gestores distritais (diretores sanitários) dessa região. A pesquisa não foi submetida ao Comitê de Ética Italiano, uma vez que, para a Itália, tratava-se de uma pesquisa com sujeitos apropriados de faculdades cognitivas que haviam firmado a sua participação por meio de consentimento livre e esclarecido. $\mathrm{O}$ anonimato dos sujeitos foi garantido pelo uso de codinomes de cineastas, construtores e seguidores do neorrealismo italiano.

Ao instrumento semiestruturado agregou-se a seguinte questão aberta: qual é a sua percepção sobre as inter-relações vivenciadas com representantes do Estado, mercado e sociedade usuária no cotidiano de práticas? 
Após transcrição fidedigna, a análise foi construída na integração dialógica de três vertentes: a epistemológica, a instrumental e a reflexiva (Minayo, 2006). A vertente instrumental correspondeu à leitura cuidadosa para apreensão dos núcleos dos sentidos que continham significações pertinentes ao objeto. Esses núcleos foram recortados em temas que se constituíram em unidades de registro, as quais, tratadas e codificadas resultaram em conflitos éticos agrupados em duas categorias de análise: conflitos éticos gerados pelo modelo de organização da atenção em saúde do SSN; e conflitos éticos gerados pela ideologia de mercado. Esta etapa foi relativizada pela criatividade, modalidade da vertente reflexiva, e fundamentada pela vertente epistemológica. Portanto, a teoria, o método, as técnicas e o pesquisador compuseram o eixo analítico entre texto e contexto, em cujo fulcro está a proposta metodológica.

A pesquisa foi aprovada pelo Comitê de Ética da Universidade Federal de Santa Catarina, sob o n. 213/2007, e realizada em consonância com as determinações da resolução CNS n. 196/1996.

\section{Descortinando conflitos éticos e analisando-os à luz da bioética cotidiana}

Na primeira categoria, conflitos éticos gerados pelo modelo de organização da atenção em saúde do SSN, emergiu o sentimento de desvalia resultante da percepção da não priorização da APS, por parte do SSN, conforme depoimento: "Se eu visse a minha profissão em relação ao Serviço Sanitário Nacional, decidiria imediatamente pela aposentadoria, não a exerceria mais; (...) aliado à mentalidade atual, o SSN se interessa somente por dinheiro" (Antonioni).

Este relato apresenta um distanciamento entre o ideário da Reforma Sanitária de 1978 e o campo do real, no contemporâneo. A luta pela saúde nas fábricas, bem como no cotidiano da vida, urbano e rural, e pela criação de organismos territoriais concretos de coordenação das atividades sanitárias parecia ter cedido aos encantos da epistemologia de saúde como bem de consumo.

A criação destes organismos territoriais representava uma dimensão da luta da classe trabalhadora, em 1978. Fortemente organizada em sindicatos, autonomias locais, grupos de médicos e enfermeiros progressistas, unidos em um esforço político-democrático das Regiões e municípios, a Reforma indicava um movimento orgânico em prol do rompimento com o sistema previdenciário de mútuas, vigente desde a Unificação italiana no século XIX (Lima et al., 2009). Um movimento de base.

O embrião de tais organismos correspondia às Unidades Locais de Saúde (ULS), criadas na década de 1960 pelo Partido Comunista Italiano (PCI) e 
apresentadas ao Parlamento italiano pelo Plano Berlinguer (Cosmacini, 2005). Este plano recomendava a criação de uma rede distrital de ULSs como opção político-social de priorização dos serviços de base, de APS. As responsabilidades das ações, até então centralizadas em institutos federais, seriam transferidas para os municípios (Itália, 1978).

No entanto, a história sanitária italiana mostra que a proposta de aproximar tais ações dos locais de produção e reprodução da vida cotidiana, no trânsito do final da década de 1960, não havia sido prioridade do Estado, pois o Parlamento italiano optara pela reforma hospitalar para oportunizar a entrada de hospitais autônomos no cenário de hospitais assistenciais e beneficentes, atendendo aos chamados de mercado (Lima et al., 2009). Liberando, deste modo, oxigênio para a falsa atmosfera triunfante do mercado que pairava no ar (Hobsbawm, 1995). Tal opção acarretou prejuízos insofismáveis ao processo sanitário, pois a reforma hospitalar de 1968 levou a uma complexa crise hospitalar e à desvalorização da medicina de família (Lima et al., 2009).

Uma nova consciência sanitária, que abraçasse a concepção de saúde como bem comum, desigualmente distribuído entre as classes sociais: essa era a imagem-objetivo do SSN (Berlinguer, Teixeira e Campos, 1988), regulamentada por meio da Lei Orgânica n. 833/1978 (Itália, 1978). Contudo, após a aprovação da lei o governo italiano não refletia o horizonte político da luta e da conquista: formado somente por membros do Partido Democrático Cristão (PDC), a dimensão social e a institucional da Reforma declinaram às intenções gerenciais e contábeis (Berlinguer, 1979).

Parece que a responsabilidade pela opção do PDC era o cenário italiano nos anos 1980, marcado por um aumento da demanda de necessidades e custos em relação ao sistema, em virtude do aumento da expectativa de vida ao nascer e, portanto, do envelhecimento populacional. A nova paisagem, somada aos efeitos da reforma hospitalar de 1968, levou a Itália a buscar medidas que pudessem resultar em condições de adequação de oferta em relação à nova demanda (Cavicchi, 2005) e, portanto, se afastasse da produção de nova consciência sanitária no afã de fazer da redução da despesa sanitária a coluna mestra do sistema.

Esse contexto fez o país adentrar a década de 1990 com instabilidade político-econômica e insatisfação de diversos setores da sociedade civil. Na leitura do Estado, a necessidade pontual de buscar soluções urgentes de adequação requeria um modelo de gestão sanitária impulsionado por administradoras regionais: o país decretou, em 1992, a Reforma de Regionalização De Lorenzo-Garavaglia (Itália, 1992), abrindo as portas ao sistema privado, que passou a ser seu grande parceiro (Berlinguer, 1979).

Ao optar por medidas políticas estruturais conservadoras, o Estado italiano promoveu um esvaziamento cultural do ideário reformista de 1978, 
alterando substancialmente o processo de construção do SSN. Dito de outra forma, o novo modelo de gestão sanitária velou as possibilidades de se descortinarem as limitações para a materialização dos ideais da Reforma e desaguou em um rompimento da relação necessidades-recursos, com pesados danos sociais e éticos (Cavicchi, 2005).

Assim, é provável que a não materialização desse ideário reformista tenha construído a representação, no imaginário de médicos de família, de um sentimento de desvalorização, fomentado pela priorização da medicina hospitalar em detrimento da medicina de família, expresso no relato de Antonioni. As fraturas éticas internalizadas pelos profissionais, resultantes dessa ausência de reconhecimento por parte do SSN, sinalizaram a emergência de outro sentimento negativo constitutivo do exercício da prática da medicina de família, o de pequenez em relação aos médicos que atuam em hospitais: "Sofro um pouco por me sentir inferior a médicos não [vinculados à medicina] de família; na estrutura hierárquica, o hospital vem primeiro" (Zavattini).

Reforçando essa observação, foi possível perceber em relatos que, para o SSN, os médicos de família representam apenas um instrumento para a histórica necessidade de contenção de despesas, como revelado por um entrevistado:

Recebemos uma carta antipática, ameaçadora do SSN (...) [afirmando que] se não respeitássemos o teto de despesa sofreríamos sanções, mas antes da tal carta ninguém tinha sonhado em nos dizer qual era realmente esse teto (...). Não trabalhamos com serenidade (...); estamos continuamente sob controle do SSN (Castellani).

Com base nesse depoimento, é possível inferir que ao conceber médicos de família como instrumento para enfrentar o déficit sanitário da região do Lácio, o Estado (des) constrói a exigência ética fundamental de que as pessoas devem ser tratadas, não como coisas, mas como pessoas, não como um meio, mas como um fim. Na perspectiva kantiana, pois: “Todo homem, porque é pessoa, existe como um fim em si mesmo (...) isto é que distingue o homem dos seres irracionais e das coisas que têm um valor relativo" (Santos e Souza, 2009, p. 79). Ou seja, se as partes não se reconhecem como iguais no tocante à dignidade, os diálogos não serão éticos.

Na mesma medida, a desconsideração da dimensão qualitativa do produto gerado pela medicina de família (Mapelli, 1999), para fins de priorização da estratégia de redução de custo, de enfrentamento à conjuntura sanitária cada vez mais cara, pautada em uma receita engessada e estreita, sinaliza que o Estado italiano compreendia saúde como um "peso para as finanças (...) um obstáculo para o crescimento da riqueza" (Berlinguer, 2011, 
p. 214), expresso no relato: “Sofremos pressão (...); somos frequentemente o ponto de descarga da necessidade de reduzir as despesas" (Tornatore).

Ao traduzir a coisificação humana e das relações sociais, este relato apresenta-se eticamente questionável. É fato que o mercado é uma realidade histórica, socialmente produzida. No entanto, saúde da coletividade não é consequência deste reconhecimento (Berlinguer, 1997), mas aspiração de todos os seres individualizados, que compõem a coletividade: um fim indivisível em si mesmo (Berlinguer, 2000). A invasão desta visão produtivista de saúde em processos de materialização de serviços/sistemas sanitários ocidentais é uma característica de sociedades capitalistas, nas quais não raramente os progressos em ato, oriundo de lutas das classes trabalhadoras, são desviados de seus cursos pelos efeitos da combinação entre o progresso científico e o livre mercado. Ciência e mercado correspondem a criações positivas da inteligência humana, mas a combinação entre ambas não tem se mostrado virtuosa (Berlinguer, 2011). Na fala de Tornatore, a vida humana se mostra coisificada pela supremacia de valores economicistas sobre os (desejados e conquistados) valores humanos.

É possível que a modalidade gerencial de racionalização proposta pela Reforma De Lorenzo-Garavaglia tenha reafirmado essa característica, ao diminuir o papel dos municípios e instituir a tecnocracia para conferir maior autonomia às regiões, que passaram a tutelar a saúde com finalidade pública (Cavicchi, 2005). É importante relevar que, em paralelo à promulgação do decreto que instituiu esse modelo de gestão sanitária, os sindicatos nacionais da medicina de família realizaram acordos coletivos e decidiram pela privatização da categoria. Os médicos de família deixaram de pertencer aos quadros de servidores municipais e assumiram o status de médicos conveniados ao SSN, com vencimentos estabelecidos por cota per capita sobre um teto-limite de cidadãos (Lima, 2008). No período de desenvolvimento da pesquisa, tal modelo acordado com os sindicatos da categoria na década de 1990 revelou-se limitado para responder com adequação ao desempenho de uma prática satisfatória, conduzindo profissionais a repensarem o modelo para a APS.

Na perspectiva da Bioética Cotidiana, balizamentos éticos e disposição para um repensar o novo cenário poderiam compor uma ética de reconhecimento, visando à materialização do real Estado laico e democrático, um Estado comprometido com os direitos humanos, a pluralidade ideológica e as finalidades comuns, no qual uma única moral conduziria o processo de viver da sociedade. Um Estado hegemonicamente comprometido com a qualidade da existência de sua sociedade (Berlinguer, 2011, 2000, 1979). Cabe assinalar que uma reforma, tal qual a italiana foi concebida, em 1978, não se materializaria se plasmada na reforma De Lorenzo Garavaglia, pautada em ações racionais puramente instrumentais, ancoradas em valores econo- 
micistas (Lima, 2008). Racionalização, normas, decretos, lei, desconectados de vontade política transformadora, não sustentam mudanças estruturais profundas (Gramsci, 2007). Embora a maior parte dos sujeitos de pesquisa tenha manifestado desencanto com a postura do SSN em relação à prática na APS, depoimentos mostraram satisfação em 'ser' médico 'de' família: "me agrada muito poder estabelecer uma relação estreita com um menino e depois (re) encontrá-lo no consultório, casado e com filhos" (Fellini).

O relato, expresso no município com menor sujeição a estímulos sociais emergentes, onde a vida parece "apressar-se de modo lento" (Lima, Verdi, 2011 , p. 151), mostra um movimento de resistência às limitações impostas pelo Estado, haja vista a não transformação do sentido autoatribuído ao cuidado e à permanência desses profissionais (que, em sua maioria, são especialistas em outras áreas médicas) no exercício da prática da medicina de família.

No entanto, o trânsito cotidiano entre o 'ser' e o 'fazer' medicina de família revelou conflitos éticos:

A minha relação com o paciente é tão profunda que, às vezes, eu me arrisco na deliberação para lhe fornecer o porto, evitando o encaminhamento ao especialista (...); com a medicina de família perdi um pouco da minha alegria e a capacidade de me conceder momentos de descontração (Puccini).

Esse relato revela disposição para a prática da medicina de família e reconhecimento de que não raramente esta prática gera implicações éticas, na relação entre o cuidado de si (do médico) e o cuidado do outro (sujeito com necessidades). A continência ao cuidado de si, configurado na cultura grega como um ideal ético, poderia atuar no enfrentamento a este mal-estar, produzido no exercício das práticas. O médico de família poderia compartilhar suas dores com um colega, por exemplo, tendo em vista que o cuidado de si é uma prática de intensificação das relações sociais, correspondendo aos "cuidados que se tem com o cuidado que os outros devem ter consigo mesmos" (Foucault, 2005, p. 58). A inserção de um colega, na tensão experimentada pelo médico de família, poderia deflagrar positividades individuais e coletivas, dentre estas, relações solidárias (Lima, Verdi, 2010) e não solitárias.

No entanto, no mesmo espaço social urbano-agrícola, de exercício da medicina de família, relatos apontaram para uma tendência à adaptação ao cenário a eles imputado e por eles construído: “É cheio de diretor contra diretor, administrador contra administrador e nesse processo eu abandonei a mim mesma (...); estou muito insatisfeita" (Pasolini).

Cabe ponderar que viver pressupõe responsabilização político-social e enfrentamento ao mal-estar inerente à vida. Nesse sentido, optar por compor 
com o SSN um acordo social com a finalidade de fazer emergir uma reconstrução orgânica de gestão, pautada na priorização da APS, ainda que com a ciência de pluralidade consensual e diferentes interesses dos atores envolvidos, poderia levar a uma ressignificação do processo de trabalho da categoria profissional (Berlinguer, 2000).

Também se fez notar o conflito de interesses entre o domínio público e privado:

Há quinze anos, o nosso sindicato fez um estudo: (...) de 100 liras gastas pelo SSN, 84 concentravam-se no hospital e 16 ficavam no território (...). O governo deveria incrementar os recursos do território e dar a gestão a quem conhece o território. E que médico conhece mais o território que o de família? O problema é que o médico de família está sempre subordinado a diretores sanitários (Castellani).

O relato permite, minimamente, duas possíveis leituras: por um lado, o entrevistado está propondo a priorização concreta da APS na agenda do Estado; por outro, sugerindo que a gestão seja conferida à medicina de família, categoria autônoma e conveniada ao SSN. Essa flutuação entre domínio público e domínio privado é alimentada pelo modelo hegemônico de organização econômica neoliberal, que define o momento em que o público deve se afastar das ações para não limitar a harmonia das relações privadas. Em outras palavras, o neoliberalismo fomenta conflitos de interesses ao promulgar o tamanho que o público deve ter diante dos interesses do domínio privado.

Outro conflito ético mencionado refere-se à limitação imposta pela política de fármacos à prática da medicina de família. Alguns medicamentos, cuja prescrição é autorizada aos especialistas, não podem ser prescritos pelos médicos de família, como segue no depoimento: (...) “Se eu desse um inibidor de bomba protônica a um paciente meu com gastrite forte, a dor passaria e eu estaria proporcionando-lhe um bem (...); porém, ao meu paciente eu devo dizer você deve comprar o medicamento (...) [com isso] estarei economizando para o SSN" (Pasolini).

Essa face da política de fármacos nega ao médico o pleno exercício profissional. Nega também ao sujeito que demanda o cuidado o direito à terapêutica necessária na perspectiva do responsável de base pelo cuidado. Ao prescrever um medicamento sem que o SSN ofereça acesso ao mesmo, como também ao optar por outra terapêutica com o fito de seguir as normativas impostas pelo Estado, o médico de família desrespeita a si mesmo e ao sujeito que a ele se dirige em busca de atenção ao seu sofrimento.

No entanto, há outra face nessa política de fármacos: a possibilidade do uso desenfreado de medicamentos para terapêuticas não específicas. Estudos sociológicos realizados a partir das décadas de 1980 e 1990 sinalizaram 
a configuração da sociedade de risco, em cujo contexto a ciência e a tecnologia são as únicas possibilidades existentes para avaliar os riscos que criam. $\mathrm{Na}$ sociedade de risco, os avanços tecnológicos ampliam os domínios do conhecimento com expressiva capilaridade, na mesma medida em que ampliam a contingência (Beck, 2011). Esse ponto de vista remete ao entendimento de que a indústria tem criado fármacos extraordinários e tecnologias de alta resolubilidade, com potenciais de sedução antes inimagináveis e suficientemente capazes de distanciar os profissionais da percepção de que as pessoas continuam dirigindo-se aos consultórios com demandas relativas ao cuidado de si mesmas com frequência igual outrora (Cosmacini, 2005).

Examinando os conflitos éticos na primeira categoria - conflitos éticos vividos pelos médicos de família em resposta ao modelo de organização da atenção em saúde do SSN -, observa-se que eles se entrecruzam com os conflitos apreendidos na segunda categoria de análise - conflitos éticos gerados pela ideologia de 'mercado'.

Um conflito encontrado diz respeito à dificuldade do médico em materializar a escolha terapêutica reconhecida como oportuna diante das novas exigências sociais. Em tempos de riscos, a velocidade dos avanços tecnológicos, a condição de perigo iminente e o incremento da contingência vêm tomando dimensões expressivas e gerando continuamente a luta insaciável por demandas e segurança. Conceitos e aspectos da vida cotidiana, produzidos e distribuídos até então nos sistemas locais, têm cedido lugar ao desenvolvimento de mecanismos de confiança em sistemas de peritos por parte da sociedade (Giddens, 2009), como estratégia para salvaguardar o 'probabilístico devir catastrófico'. A demanda de medicamentalização e de exames sofisticados por parte da sociedade pode ser entendida nessa lógica, conforme revelado:

Há má política sanitária, mas há também má sociedade de usuários (...). As pessoas (...) dizem: "Ah, o meu vizinho tinha uma dor e fez uma ressonância. Eu também quero." Em três anos, perdi 150 mutuários porque não prescrevia aquilo que não via como adequado e necessário (Pasolini).

Observa-se que a condição de resistir ou ceder às pressões impostas ao processo de trabalho com o propósito de sustentar ou ressignificar as escolhas percebidas como coerentes é parte do cotidiano da interação de profissionais com sujeitos em seu processo de cuidado. Entendeu-se que essa condição, posta como parte do real, está vinculada à concepção de saúde não como um bem ético, mas mercadoria, um bem de consumo: "Se você minimamente lhe diz: 'Escuta, espera um pouco pra fazer exames, vamos tentar tal tratamento antes', estabelece-se entre você e o paciente um muro (...); a saúde virou um mercado onde muitos lucram bastante" (Castellani). 
Em Etica della salute, Giovanni Berlinguer (1997) escancara com rigor ético-político a corrida desmedida do homem por avanços tecnológicos e a coisificação humana e das relações sociais. Critica a união estável entre Estado e mercado que, à luz neoliberal, constrói cotidianamente uma nova ordem social que limita movimentos de luta, em prol da consolidação da garantia do direito à saúde como direito humano. Com base nessa obra, é possível inferir que o 'muro' mencionado no último depoimento pode ser entendido como um dispositivo desta nova ordem social.

Outro conflito ético que se fez presente foi o poder de sedução exercido por representantes de laboratório. Os depoimentos revelaram que esses profissionais estão presentes diariamente nos consultórios, visando garantir seus produtos no mercado, e, para tal, utilizam-se de diferentes medidas, inclusive coercitivas:

Os mais novos tentam nos pressionar (...). Chegam e dizem (...): “Ah, a molécula que a outra empresa produz não é tão boa como a nossa" (...); eles precisam entender que medicina não significa prescrição (...) Nós ganhamos computadores das indústrias farmacêuticas (Castellani).

Nesse sentido, percebe-se a forte pressão exercida pela indústria farmacêutica no exercício profissional. Ao relatar a necessidade dos representantes de laboratórios entenderem que a medicina de família não é prescritiva, o médico de família sinaliza movimentos de prática conectados ao conceito ampliado de saúde e demonstra ciência quanto ao papel sedutor e coercitivo da indústria, na tentativa de esvaziar tal modelo e buscar fonte de lucro para os seus interesses.

Entretanto, é importante refletir que a fonte desse conflito ético se encontra também em nível macro, uma vez que a força do mercado farmacêutico presente nas sociedades de risco, hegemonicamente neoliberais, advém do espaço a ele concedido por aquele que se mostra comprometido com eficiência, eficácia e efetividade; por aquele legitimado pela sociedade para representá-la: o Estado.

A maior parte dos entrevistados mencionou o papel da mídia como um recurso de difusão de conceitos neoliberais. Ao difundir-se na cultura ocidental, esse veículo publicitário parece deter uma autoridade capaz de construir uma representação social coletiva e autônoma, gerando um conflito ético como fruto de uma nova ordem de demanda social: "[Os pacientes] vêm ao consultório para nos fazer uma proposta terapêutica ou diagnóstica que, às vezes, não advém de um mal-estar, de uma indisposição ou de uma doença, mas simplesmente porque ouviu na televisão (...); se recusamos, viramos inimigos" (Rossellini).

Com base nesse relato, é possível entender que a mídia se coloca como um terceiro sujeito no espaço quase sagrado da relação entre médico de famí- 
lia e sujeito. Ainda que este setor contemple o direito à informação e produza bens, é inegável a sua capacidade de construir 'o acontecer no devir humano' enquanto 'filha' desse modelo de mercado, gerando indiretamente outro conflito ético: a responsabilização da sociedade por limitar o exercício de uma medicina do bem por médicos de família: “Eu me agarrei a esse trabalho com um grande entusiasmo, mas a maturidade me fez perceber que quem faz a medicina do bem não pode pagar as despesas de casa" (Pasollini).

Hans Jonas, ao descrever analiticamente o princípio da responsabilidade, assinalou que diante da hegemonia do discurso tecnológico as ameaças ao indivíduo e à espécie humana "não vêm mais da natureza nua, mas do poder perseguido para dominá-la" (Berlinguer, 2011, p. 43). De forma dialética, o homem tornou-se um perigo para a natureza, na cegueira da compreensão de ser ele natureza também. Deixando de ser uma esfera neutra da natureza humana e passando a reter a emancipação humana em processos de sujeição, a tecnologia "se transforma, de modo inelutável, objeto da ética" (Berlinguer, 2011, p. 44). O princípio da responsabilidade, de Jonas, correspondendo a um guia ético do agir singular humano, com base em um universal dele dependente, é uma possibilidade para refletir os vazios, expostos no depoimento sobre a medicina 'do bem'.

A utilização desenfreada do pronto-socorro, em horários noturnos, para fins de realização de exames de especialidades sem pagamento de ticket, foi relatada como moralmente inaceitável, uma vez que acarreta abusos e desperdícios ao sistema.

O ticket corresponde a um sistema de coparticipação da sociedade italiana para integrar o financiamento do SSN, visando à garantia dos seguintes itens, para pessoas consideradas isentas e de baixa renda: a) consultas e exames solicitados nas diversas especialidades; b) exames requeridos pela medicina de família e; c) despesas farmacêuticas. Esta modalidade de coparticipação, instituída por decreto, em 1982 (Itália, 2015), foi regulamentado pela lei n. 537/93, um ano depois da instituição da Reforma De Lorenzo Garavaglia (Lima et al., 2009).

A partir da Lei Orçamentária de 2007, os atendimentos realizados em pronto-socorro não seguidos de internação são isentos de pagamento de ticket e ofertados por meio de um código branco, sem necessidade, portanto, de pagamento (Itália, 2006). Esta prerrogativa tem levado as pessoas a procurarem o pronto-socorro e realizarem consultas com especialistas e exames sem pagamento:

Como não se paga o ticket no pronto-socorro, os pacientes aproveitam a fresca das noites de verão, passam a noite lá [no pronto-socorro] e fazem todos os exames gratuitamente (Pasollini) (...): Você paga, eu pago, sua mãe paga, sua avó paga, todos nós pagamos (De Robertis). 
Em que pese a responsabilização da sociedade pelos gastos do sistema, mencionada no depoimento anterior, o fato social pode ser lido como uma deficiência da organização do SSN, pois, se o Estado decreta a isenção de ticket em pronto-socorro, para os italianos pagantes de impostos e os isentos, a medida se impõe como direito de todos. Nesta leitura, independentemente se os serviços usados no pronto-socorro são consultas com especialistas e/ou exames especializados, a sociedade usuária não estaria recebendo uma benevolência do Estado, mas exercendo um direito. A implicação ética, nesta lógica, recai sobre o Estado, e o vazio parece estar na organização das ações de base da APS. Os relatos coletados revelaram que o sistema neoliberal, ao 'condenar' o homem ao engessamento e à cristalização de potencialidades, alimenta historicamente conflitos éticos e produz uma nova tipologia social, impulsionada por um processo de sujeição político-social, de (re)invenção de necessidades e de submissão a riscos probabilísticos, criado por um poder outorgado às sociedades capitalistas, até então inatingível, chamado mercado.

Embora os médicos de família, os representantes da sociedade no SSN e a sociedade sejam sujeitos político-sociais, o que se observa nesta análise é uma sujeição coletiva ao novo sujeito (re)inventado pelo neoliberalismo. A maior parte dos entrevistados responsabiliza diretamente o Estado e a ideologia de mercado, e, indiretamente, a sociedade, pelos conflitos éticos que circunscrevem a sua prática, justificando esses conflitos com argumentos claros e coerentes.

Um sujeito da pesquisa expressou o desejo de exercer uma medicina 'do bem'. Ao expressar o desejo de exercer uma medicina 'do bem', esse médico revelou limitações na materialização da medicina de família, sugerindo a existência de outra face de prática médica que poderia ser a fonte geradora dessas limitações. Com base na construção desse olhar de 'medicina do bem', pode-se pensar a outra face, talvez uma medicina 'do mal', provavelmente aquela construída pela hegemonia de 'mercado'. Esta hegemonia tem como eixo nuclear um imperativo categórico peculiar, constituído pela transformação da humanidade em mercadoria pelo mercado, que, por sua vez, encanta o Estado com o seu pátrio poder de reinvenção de um novo sujeito-consumidor e com o seu discurso de salvador de finanças.

Retomando a Bioética Cotidiana, na relação com o objeto deste estudo, a ausência de articulação entre a medicina de família italiana e o Estado estreita o horizonte de possibilidades políticas, sociais e culturais, tão necessário para a transformação do cenário percebido como socialmente insalubre em um cenário saudável e justo. Quando este horizonte é delineado na convivência responsável e no respeito à pluralidade de desejos/necessidades, as possibilidades de concretude se ampliam (Berlinguer, 2011, 2000). 


\section{Considerações finais}

Na delimitação deste estudo, médicos de família revelaram duas linhas de reconhecimento de conflitos éticos entrecruzadas nas inter-relações vivenciadas no processo de trabalho.

Em uma primeira linha, a maior parte apontou para uma lacuna nas relações entre o Estado e a categoria; em um segundo momento, médicos de família revelaram a pressão exercida diretamente pelo Estado e pela ideologia de mercado, e indiretamente pela sociedade, no exercício da medicina de família.

Foi possível apreender que, embora o esforço para evitar o escoamento de suas potencialidades mediante movimentos de resistência seja visível, os profissionais se deparam em seus processos de produção e reprodução com uma força que parece transcender as suas aptidões. Essa força se mostra como uma sombra sobre o real da prática da medicina de família: a ordem social neoliberal, aquela apartada do bem comum e que legitima a reinvenção de novos sujeitos sociais, insaciados, ansiosos e temerosos, detentores de uma subjetividade não produzida na relação de encontro com o outro, mas pós-humana.

O modelo ideológico do Estado italiano, assim como os demais Estados neoliberais, apresenta limitações no arranjo de sua superestrutura que obstaculizam a efetiva composição entre seus atores sociais. O diálogo político parece flutuar na esfera do desejo de alguns e na representação ilusória e alienação de outros. Passados 37 anos da conquista social da Reforma Sanitária de 1978, percebe-se o distanciamento entre o ideário do movimento e as escolhas políticas explicitadas na materialidade. A ordem social para garantir a produção de saúde é: "Devemos atuar no déficit sanitário do Lácio reduzindo as despesas" (Castellani).

Médicos de família deste estudo exercem suas atividades nesse cenário de poderio neoliberal e mostram fragilidades e fendas promotoras de um distanciamento entre as dimensões 'ser' médico de família e 'fazer' medicina de família. A grande maioria expressa com prazer uma real satisfação em 'ser' médico de família e um desencanto em 'fazer medicina de família' no contexto atual.

Esse desencanto em 'fazer medicina de família' é alimentado por um sentimento de marginalidade em relação à posição ocupada, no SSN, pelos médicos especialistas e pelos que exercem suas práticas em hospitais. O sentimento oscila entre movimentos de resistência e de concessão - os quais podem interferir não apenas no exercício de uma prática pautada na saúde da vida pulsante (porque concreta do tempo presente), isto é, na saúde como valor democrático, mas também na 'eficácia' tão desejada pelo SSN.

Refletindo sobre o processo de viver, percebe-se que o sentimento de marginalidade detém positividades, uma vez que impulsiona o crescimento, 
estimulando a criatividade e ações transformadoras. Nessa lógica, parece provável que o sentimento gerado pela indiferença do SSN estimule a preservação dessa prática, da mesma forma que a escola médica polonesa mostrou ao mundo, em 1920, uma notória concepção de medicina em razão da marginalidade em que se encontrava e da distância que separava as suas aspirações profissionais das possibilidades práticas de realização (Löwy, 1990).

Contudo, pode-se pensar que os conflitos éticos poderiam ser pulverizados ou minimizados pela maximização do comprometimento ético-político para com a própria vida e para com a vida do outro. Esses profissionais poderiam usar o espaço de cuidado também como espaço de construção, de luta e de educação política, entre seus pares e demais sujeitos. Desse modo, estariam lutando contra o 'novo ser inventado pelo modelo neoliberal', visando ao lançamento de sementes para a construção de uma consciência crítica coletiva que pudesse vislumbrar um processo de mudança. Um processo de construção coletiva.

Na perspectiva da análise gramsciana da teoria da hegemonia (Gramsci, 1981), seus intelectuais orgânicos, em consenso com o Estado, poderiam refletir sobre os efeitos causados pela sombra do neoliberalismo na política do SSN, pensando a responsabilidade político-social como um exercício ético e, ao mesmo tempo, vislumbrando um horizonte comum a ser alcançado por meio de disponibilidade interna e união coletiva. Desse modo, poder-se-ia lançar, no interior dessa nova hegemonia, um imperativo ético norteador para o enfrentamento de fragilidades e fendas, elementos constitutivos das inter-relações, aproximando assim o 'ser' e o 'fazer' na prática da médica de família.

Considerando que tal possibilidade é "também uma realidade" (Gramsci, 1981, p. 47), ela poderá deflagrar um ambiente facilitador de potencialidades: a satisfação pessoal, e, em consequência, a satisfação profissional; o sentimento de cumprimento do valor da ética enquanto sujeitos político-sociais; o estímulo para mostrar ao SSN que a medicina de família 'é' uma área de atenção em saúde cujo produto sanitário, em um sistema efetivamente comprometido com a concepção de saúde como valor democrático, é prioritário e exige dignidade; o fortalecimento para enfrentar a face perversa do mercado; o reconhecimento social; e, especialmente, o entusiasmo para 'fazer' medicina de família e sentir-se exercendo 'a sua prática médica' cujo processo histórico é um exemplo para o mundo. Uma prática médica de pessoa para pessoa e entre pessoas na qual a "pílula mágica" (Rossellini) é o encontro. De almas unidas e não (como relata Pasolini) "de almas perdidas". Comprometida historicamente com o cuidado. Construída na delicadeza. 


\section{Colaboradores}

Rita de Cássia Gabrielli Souza Lima responsabilizou-se pela construção do artigo em todas as etapas; Marta Inez Machado Verdi participou da discussão e revisou o texto. A pesquisa foi realizada sem financiamento. Não há conflitos de interesse.

Resumen El artículo examina las fragilidades que permean las interrelaciones establecidas en el proceso de trabajo de médicos de familia italianos para conocer posibles conflictos éticos. Se trata de un estudio de campo, de enfoque cualitativo, y de carácter exploratorio-descriptivo, realizado en 2007 en la provincia de Roma, región del Lacio, Italia, con médicos de familia italianos asociados con el Servicio Sanitario Nacional. Analizados a la luz de la bioética cotidiana, los resultados muestran conflictos éticos generados directamente por el modelo de organización de la atención en salud del Servicio Sanitario Nacional y por el mercado de la industria farmacéutica e indirectamente por la sociedad, teniendo como telón de fondo el capitalismo en su aspecto neoliberal.

Palabras clave médicos de familia; la bioética; capitalismo.

\section{Notas}

1 Universidade do Vale do Itajaí, Itajaí, Santa Catarina, Brasil.

Doutora em Saúde Coletiva pela Universidade Federal de Santa Catarina.

<rita.lima@univali.br>, <rcgslima@gmail.com.br>

Correspondência: Universidade do Vale do Itajaí, Rua Uruguai, 458, bloco F6, sala 311, Centro, CEP 88302-202, Itajaí, Santa Catarina, Brasil.

2 Universidade Federal de Santa Catarina, Trindade, Florianópolis, Santa Catarina, Brasil.

Doutora em Enfermagem pela Universidade Federal de Santa Catarina.

<marta.verdi@ufsc.br>, <marverdi@hotmail.com> 


\section{Referências}

ABBAGNANO, Nicola. Dicionário de filosofia. São Paulo: Martins Fontes, 2007.

BARDIN, Laurence. Análise de conteúdo. Lisboa: Edições 70, 1977.

BECK, Ulrich. La società del rischio. Urbino: Carocci, 2011.

BERLINGUER, Giovanni. Storia della salute. Da privilegio a diritto. Firenze: Giunti, 2011.

BERLINGUER, Giovanni. Bioetica quotidiana. Firenze: Giunti, 2000.

BERLINGUER, Giovanni. Una riforma per la salute. Bari: De Donato, 1979.

BERLINGUER, Giovanni. Etica della salute. Milão: Saggiatore, 1997.

BERLINGUER, Giovanni; TEIXEIRA, Sonia F.; CAMPOS, Gastão W. S. Reforma sanitária: Itália e Brasil. São Paulo: Hucitec, 1988.

CAVICCHI, Ivan. La sanità. Bari: Dedalo, 2005.

COSMACINI, Giorgio. Storia della medicina e della sanità in Italia. Roma: Laterza, 2005.

FOUCAULT, Michael. História da Sexualidade 3: o cuidado de si. São Paulo: Graal, 2005.

GIDDENS, Anthony. A constituição da sociedade. São Paulo: Martins Fontes, 2009.

GRAMSCI, Antonio. Quaderni del carcere. 3. ed. A cura di Valentino Gerratana, v. 3. Torino: Einaudi, 2007.

GRAMSCI, Antonio. Concepção dialética da história, 4 ed. Rio de Janeiro: Civilização Brasileira, 1981.

HOBSBAWM, Eric. A era dos extremos: o breve século XX (1914-1991). São Paulo: Companhia das Letras, 1995.
ITÁLIA. Ministero della Salute. Ticket ed esenzione. 2015. Disponível em: <www. salute.gov.it/portale/salute/p1_5.jsp?id= $34 \&$ area $=$ Il_Ssn $\&$ menu $=$ cittadino $>$. Acesso em: 14 mar. 2015.

ITÁLIA. Ministero della Salute. Legge finanziaria 2007. Roma: Ministero della Salute, 2006. Disponível em: <www.parlamento. it/parlam/leggi/06296l.htm>. Acesso em: 14 mar. 2015.

ITÁLIA. Ministero della Salute. Decreto legislativo n. 502 de 30 dicembre 1992. Roma: Ministero della Salute, 1992. Disponível em: <www.gazzettaufficiale.it/eli/id/1994/01/07/ 094A0049/sg >. Acesso em: 14 mar. 2015.

ITÁLIA. Ministero della Salute. Servizio Sanitario Nazionale. Legge n. 833 de 23 dicembre 1978. Disponível em: <www. salute.gov.it/imgs/C_17_normativa_231_ allegato.pdf $>$. Acesso em: 2 mar. 2011.

LIMA, Rita de C. G. S.; VERDI, M. Giovanni Berlinguer: uma história de luta pelo direito à saúde. In: HELLMANN, Fernando; VERDI, Marta; LIMA, LIMA, Rita C. G. S.; CAPONI, Sandra. Bioética e Saúde Coletiva, 2. Ed. Curitiba: PRISMAS, 2013. p. 15-32.

LIMA, Rita de C. G. S.; VERDI, M. I. M. Reflexões sobre a relação entre saúde e sociedade no contexto contemporâneo italiano. Revista Bioética (impressa), v.19, n.1, p. 157, 2011.

LIMA, Rita de C. G. S.; VERDI, M. Solidarity in family medicine in Brazil and in Italy: reflecting on ethical issues and contemporary challenges. Interface: Saúde, Educação, Comunicação, Botucatu, v. 5, selected edition, 2010.

LIMA, Rita de C. G. S. Concepções de médicos de família no Brasil e na Itália sobre autonomia e solidariedade: implicações éticas para o cuidado na atenção primária de saúde. 175f. 2008. Dissertação (Mestrado 
em Saúde Pública) - Programa de Pós-graduação em Saúde Pública, Centro de Ciências da Saúde, Universidade Federal de Santa Catarina, Florianópolis, 2008.

LIMA, Rita de C. G. S. et al. A construção do direito à saúde na Itália e no Brasil na perspectiva da bioética cotidiana. Saúde e Sociedade, São Paulo, v. 18, n. 1, p. 118-130, 2009.

LÖWY, Illana (Ed.). The Polish School of Philosophy of Medicine. From Tytus Chalubinski (1820-1889) to Ludwik Fleck (1896-1961). Netherlands: Kluwer Academic Publishers, 1990.
MAPELLI, Vittorio. Il sistema sanitário italiano. Bolonha: Il Mulino, 1999.

MINAYO, Maria C. dos S. O desafio do conhecimento: pesquisa qualitativa em saúde. 12. ed. São Paulo: Hucitec, 2010.

TURATO, Egberto R. Tratado da metodologia da pesquisa clínico-qualitativa: construção teórico-epistemológica discussão comparada e aplicação nas áreas da saúde e humanas. Petrópolis: Vozes, 2003.

Recebido em 12/08/2011

Aprovado em 21/05/2014 
